\title{
Artigo
}

\section{Assimetrias da política externa russa para a Crimeia e a Transnístria}

\section{Russian foreign policy's assymmetries toward Crimea and Transnistria}

DOI: 10.5752/P.1809-6182.2016v13.n2.p102

Renata Corrêa Ribeiro ${ }^{1}$

\section{RESUMO}

Recebido em: 10 de março de 2016 Aprovado em: 11 de agosto de 2016

Este trabalho visa identificar o porquê de haver distinçôes no tratamento da Rússia aos casos da Crimeia e da Transnistria. O objetivo central é verificar se as circunstâncias são similares e se Vladimir Putin, após a anexação da Crimeia, faria o mesmo com a Transnistria.

Palavras-chave: Rússia. Crimeia. Transnistria.

\section{ABSTRACT}

This work aims to identify why Russia behaves differently towards the cases of Crimea and Transnistria. The main goal is to verify if both cases are similar and if Vladimir Putin, after the annexation of Crimea, could take the same step in relation to Transnistria.

Keywords: Russia. Crimea. Transnistria.

1. Doutoranda em Relaçôes Internacionais pela Universidade de Brasília (UnB), Mestre em Relaçôes Internacionais pela Universidade Federal da Bahia (UFBA) e Bacharel em Relaçóes Internacionais pela Universidade de Vila Velha (UVV). Realizou intercâmbio na Hogskolen i Sor-Trondelag (HiST) na área de Economia e Negócios Internacionais, em Trondheim, na Noruega. orcid.org/0000-0001-6577-4398 
Em Março de 2014, o mundo assistiu perplexo à anexaçẫo da região ucraniana da Crimeia pela Rússia. Foi o produto final da manobra política ucraniana de deposição do presidente pró-russo Viktor Yanukovych, percebida pelo Kremlin como uma tentativa do Ocidente de minar a influência russa na regiáo. A Crimeia fez parte da União Soviética até 1954 , quando o então dirigente russo Nikita Khruschov decidiu fazer um gesto simbólico para garantir o apoio dos ucranianos, oferencendo-a à Ucrânia.

A questão da Crimeia, no entanto, não é um caso isolado. Outras regióes clamam por maior autonomia desde o fim da Uniâo Soviética (URSS): Transnístria e Gagáuzia (Moldávia), Ossétia do Sul e Abecásia (Geórgia) e Nagorno-Karabakh (enclave armênio no território do Azerbaijão). Dentre as citadas, cabe especial atenção ao caso transnístrio. A Transnístria é uma região autônoma no Leste da Moldávia, com área de apenas $1.600 \mathrm{Km}^{2}$. A autoproclamada "República da Transnístria" é permanente foco de tensão e instabilidade, constituindo elemento central no relacionamento bilateral Rússia-Moldávia.

Ao comparar os casos da Transnístria e da Crimeia, percebem-se grandes semelhanças, o que levou à especulação do comando da Organização do Tratado do Atlântico Norte (OTAN) e de analistas internacionais de que, após a anexação da Crimeia, Moscou poderia seguir os mesmos caminhos na Moldávia, interferindo no conflito da Transnístria com o objetivo de anexá-la. O propósito deste artigo é demonstrar que, apesar das semelhanças entre os casos da Crimeia e da Transnístria, o interesse da Rússia é distinto nas duas situaçóes. Como afirma Mefford (2014), a Rússia já obteve o que desejava com a anexação da Crimeia e é improvável que anexe outros territórios devido à falta de benefícios que essa ação poderia trazer ao país.

\section{A crise ucraniona e a anexação da Criméia}

A anexação da Crimeia pela Rússia foi um evento singular, que ensejou uma nova era nas relaçóes internacionais. Com a crise ucraniana, a geopolítica voltou a ser o centro dos cálculos de política externa das grandes potências, marcando um novo período de forte rivalidade nas relações Rússia-Ocidente. Dmitri Trenin (2014) aponta as raízes da crise:

A crise ucraniana foi precedida por uma competição entre a Uniấo Europeia e a Rússia pela orientação geoeconômica futura da Ucrânia. As raízes da crise encontram-se na guerra de 2008 entre a Rússia e a Geórgia, que pôs fim à ideia de expansão da OTAN tanto para a Geórgia quanto para a Ucrânia, e no início da crise financeira global, que pareceu dar mais credibilidade a arranjos econômicos regionais. Os europeus, por meio do programa Eastern Partnership, que a Uniāo Europeia lançou em 2009, buscaram a associação a Ucrânia. No entanto, ao invés de ser um passo em direçấo a uma futura ampliação da União Europeia, essa iniciativa foi uma tentativa de constituir uma "zona de conforto" para o leste das fronteiras da união e reforçar a orientação ocidental desses países. A Rússia, por sua parte, tentou atrair a Ucrânia e a maior parte dos outros países da ex-URSS para seu projeto de uma união aduaneira, também iniciado em 2009, que levou, em maio de 2014, à assinatura do tratado estabelecendo a Uniáo Econômica Eurasiática (TRENIN, 2014, p. 04, TRADUÇÃO NOSSA).

Assim, tanto Bruxelas quanto Moscou viam a Ucrânia como um importante elemento de seu projeto geopolítico. Viktor Yanukovich, presidente ucraniano desde 2010, manteve postura de aproximaçāo com a Rússia desde o início de seu governo, mas a decisão de abandonar as negociaçôes dos acordos comerciais e de associação com a União Europeia (UE), em novembro de 2013, para aderir a uma iniciativa econômica russa encontrou 
forte reação da população ucraniana. Os protestos tomaram grandes proporçóes, espalhando-se para diversas regiôes do país. Como ressaltado por Mielniczuk (2014), a UE teve papel destacado no alastramento da crise, graças ao constante incentivo à tomada das ruas pelos manifestantes.

As manifestações e as pressões do Ocidente levaram à destituição do governo democraticamente eleito de Yanukovich em março de 2014, em favor de um presidente interino, cujo governo de transição foi prontamente reconhecido por EUA e UE (MIELNICZUK, 2014). A população pró-Rússia, temendo a expansão dos movimentos ultranacionalistas e a proibição do uso do russo como língua oficial $^{2}$, dominou o Parlamento local, nomeando um premiê. O novo governo, que não foi reconhecido pela Ucrânia, aprovou a anexaçáo da Crimeia à Rússia em março de 2014, após referendo com 96,77\% de aprovação (BEBLER, 2015). Em poucos dias, o governo de Vladimir Putin oficializou a incorporação e passou a considerar a Crimeia parte da Federação Russa.

A pronta anexação e o apoio de Moscou aos sentimentos autonomistas em diversas regióes da Ucrânia suscitaram manifestaçôes do Ocidente contra a interferência russa nos assuntos internos da Ucrânia e a violaçáo do princípio da integridade territorial. A gênese da crise ucraniana, contudo, é muito mais profunda e revela um embate entre a Rússia e o Ocidente pela influência naquela regiāo. A Rússia age em defesa de seus interesses e de seus nacionais fora do território russo, enquanto o Ocidente (principalmente OTAN e UE) tentam impedir o crescimento da influência russa, por motivos geopolíticos e econômicos. Com isso, as relaçóes Rússia-Ocidente estremeceram-se, com o agravamento provocado pelas

2. Um dos primeiros atos do governo de transição pró-Ocidente na Ucrânia foi a abolição da lei "On State Language Policy", instituída por Yanukovich em 2012. Essa lei permitia que as regiốes do país usassem mais línguas oficiais (que poderia ser o russo, ucraniano, húngaro, romeno etc) se elas fossem faladas por, no mínimo, $10 \%$ dos habitantes daquela região. 13 das 27 regiōes ucranianas adotaram o russo como segunda língua oficial, como a Crimeia e áreas ao leste do país. No entanto, de acordo com Bebler (2015), essa lei foi vetada pelo presidente interino do país e, portanto, nunca teve efeitos reais. sançôes impostas à Rússia e a dificuldade em se negociar o fim da crise ucraniana.

\section{A questão transnístria}

O conflito na Transnístria assemelha-se ao caso da Crimeia no que tange à nova lei linguística. A agitaçâo pela independência iniciou-se após a adoção, em 1989, de leis que visavam à "desrussiffcação" da Moldávia, prevendo o estabelecimento do moldavo como a língua oficial do país e a transiçáo do alfabeto cirílico para os caracteres latinos. González (2001) adiciona outras razóes que fomentaram ideais separatistas:

Um elemento característico do caso moldavo é a fragilidade numérica da população russa. Esse fato é particularmente importante e, talvez, a razão pela qual a violência se desencadeou com rapidez. A sensação de insegurança da população russa de meio milhão de pessoas inflamou as posiçóes radicais (GONZÁLEZ, 2001, p.40, TRADUÇÃO NOSSA)

Em 1990, após um referendo com 97,7\% de apoio, a Transnístria autoproclamou-se independente. O pequeno território historicamente eslavo receava a unificação da Moldávia com a Romênia e temia que reformas políticas e econômicas aniquilassem o modo de vida socialista e os privilégios socio-políticos da elite transnístria. Deve-se salientar que a regiáo constitui apenas $12 \%$ do território da Moldávia, mas contém $17 \%$ de sua população e gera $35 \%$ de todo o rendimento nacional (FREIRE, 2011). A declaração de independência da Transnístria não foi reconhecida nem pelo governo central de Chisinau, e nem por nenhum Estado soberano.

Após o colapso da URSS e a independência da Moldávia, a tentativa do governo central moldavo de controlar a região da Transnístria levou à guerra civil em 1992. As forças moldavas, contudo, foram facilmente derrotadas pelas tropas transnístrias, que receberam equipamento, apoio 
e instruçóes do $14^{\circ}$ Exército Russo estacionado na área desde $1945^{3}$. Após quatro meses de conflitos, Chisinau e a Transnístria chegaram a um acordo de paz. Foi definida uma área de segurança ao longo do Rio Dniestre e determinado o envio de forças de manutenção de paz tripartites: russas, moldavas e transnístrias. $\mathrm{O}$ acordo estabelecia ainda o princípio da integridade territorial e de soberania da Moldávia, além da necessidade de definir um status especial para a região separatista (FREIRE, 2011).

É importante salientar que nos primeiros anos após a desintegração da URSS, Moscou buscou evitar o envolvimento no conflito transnístrio. Devido à crise econômica, a Rússia ficou fragilizada no sistema internacional. A única solução para seus problemas internos foi procurar a colaboração das potências ocidentais. Para o Kremlin, a ajuda apenas seria concedida se a Rússia mostrasse que não intencionava restaurar o poderio soviético. Dessa forma, Yeltsin e Andrei Kosyrev, Ministro das Relaçôes Exteriores, implementaram uma forma de isolamento em relação aos ex-Estados soviéticos, que acabou por se traduzir no afastamento do conflito transnístrio. Todavia, essa política isolacionista em relação aos países do espaço soviético foi repelida internamente. Os russos associavam as dificuldades econômicas e a perda do poderio internacional à figura de Yeltsin que, cercado por uma equipe pró-Ocidente liderada por Kosyrev, promoveu reformas democráticas e passou a criticar o passado czarista e soviético da nação, associando o modelo ocidental como o ideal.

Foi só a partir de 1996, quando da queda de Kosyrev, que ocorreram mudanças profundas na política externa russa em relação ao caso transnístrio. Yevgeny Primakov tornou-se Ministro das Relaçôes Exteriores e rompeu definitivamente com o isolacionismo, iniciando uma orientação mais assertiva em relação ao conflito, devido, principalmente ao temor de expansão da OTAN. Desde então, a Rússia utiliza uma estratégia geopolítica

3. Segundo Freire (2011), a área em que o batalhão russo estava estacionado é uma zona estratégica de importância para a Rússia, localizado na fronteira com a Europa e com os Bálcâs. para a questão transnístria: não interferir no conflito, de forma a deixar a crise patente para impedir o avanço da OTAN para as bordas da Moldávia. Cumpre destacar que a OTAN não aceita membros com problemas fronteiriços, o que impossibilitaria a aceitação de Chisinau como membro pleno da organização.

Até o momento, não se alcançou um acordo definitivo sobre o estatuto da Transnístria. Chisinau dispóe-se a atribuir ampla autonomia e poderes alargados a Tiraspol, mas recusa a proposta patrocinada pela Rússia do Memorando Kozak, de 2003, que previa a federalização do país. O presidente Putin, por sua vez, mantém apoio incontestável à proposta, que abarcaria a Moldávia, a Transnístria e a Gagáuzia (FREIRE, 2011; KALJURAND, 2008).

A presença de tropas russas também dificulta as negociaçóes. Para a Moldávia, os cerca de 2.500 militares russos em seu território representam ocupação estrangeira e ameaça à unidade nacional. Já a Transnístria é amplamente desfavorável a qualquer acordo que impute a retirada dos militares. A Rússia, por seu turno, condiciona a retirada das tropas à definição de um acordo político. Em 1999, durante a Cúpula de Istambul da Organização para a Segurança e Cooperação na Europa $(\mathrm{OSCE})^{4}$, o governo russo prometeu retirar suas tropas da Moldávia até 2002. Até o momento, contudo, poucos oficiais e equipamentos militares foram desmobilizados (NYGREN, 2007).

Desde a ascensão de Putin como presidente, em 2000, diversas tentativas de negociação sem sucesso têm sido conduzidas. Em geral, elas contam com a presença de Rússia, Ucrânia, EUA, UE e a OSCE (Formato 5+2). Com isso, a Transnístria permanece um "conflito congelado" (segundo o Conselho da Europa), alcançando sua independência apenas de facto, sem reconhecimento por parte de nenhum país membro da ONU (FREIRE, 2011; NYGREN, 2007).

4. Organização para a Segurança e Cooperação na Europa 


\section{As semelhanças intrínsecas nos casos da Crimeia e da Transnístria}

Em 2006, a governo transnístrio conduziu um referendo em que $96 \%$ dos votantes optaram pela unificação da região com a Rússia (CIOBANU, 2007), mas as autoridades russas não apoiaram a medida. A anexação da Crimeia, em 2014, tornou-se um grande precedente - tanto para os transnístrios quanto para os analistas em política externa - de que Moscou poderia agir de forma semelhante na Moldávia. Assim, em março de 2014, representantes do Parlamento de Tiraspol adotaram nova resoluçáo requisitando a admissão da área de $4.000 \mathrm{Km}^{2}$ como parte da Federação Russa, pedido que, novamente, obteve o silêncio das autoridades russas.

A atitude do regime transnístrio foi motivada pela maior aproximação entre a Moldávia e a UE, com a assinatura do Acordo de Associação em Junho de 2014. De acordo com Mefford (2014), o status da Moldávia de país "mais pobre da Europa" e a falta de opçôes de viagens para os cidadãos da Transnístria contribuíram para que a região se mantivesse isolada de influências externas desde 1992. A abertura das fronteiras da Europa para a entrada de moldavos sem a necessidade de visto é entendida como uma fonte irreversível de distanciamento dos transnístrios com a Rússia, pois, com o acesso facilitado à Europa, a Transnístria começará a perder o apoio da populaçáo, que se mantém alheia aos acontecimentos do mundo devido ao forte controle da mídia exercido pelo regime separatista de Tiraspol. Para as autoridades da Transnístria, portanto, não há momento mais favorável para buscar a anexação à Federação Russa, pois, assim como a Ucrânia, há chances de a Rússia perder sua influência em uma área tão estratégica.

As similaridades entre Crimeia e Transnístria levam os analistas internacionais a acreditarem que o
Kremlin possui um desejo semelhante de anexação. No que tange às questôes identitárias, ambas as regiôes contém uma maioria russa (ou de descendentes de russos) significante, um passado compartilhado, a língua russa está amplamente disseminada e a religião predominante é um ponto que une as duas áreas a Moscou. Assim, a Rússia poderia invocar o princípio básico de sua Concepção de Política Externa, que garante uma "proteçấo abrangente dos direitos e interesses legítimos dos cidadãos russos e compatriotas residindo no exterior" (RÚSSIA, 2013). Vale ressaltar que Vladimir Putin utilizou essa justificativa para anexar a Crimeia, afirmando que "reserva-se o direito de proteger os russos étnicos que vivem na Ucrânia” (ENGLUND; LALLY, 2014).

Em relação à geopolítica, as similitudes mantêm-se. Ambas as áreas são vistas como essenciais pela Rússia para alcançar um objetivo maior de política externa. Para Moscou, é imprescindível manter a Crimeia sob seu domínio, pois o Mar Negro é a única saída do território russo para os mares quentes e a principal rota de passagem para seus principais parceiros comerciais: os países europeus. Ademais, em Sevastopol está estacionada sua principal frota naval, localizada estrategicamente para impedir qualquer aventura ocidental na zona de influência russa. O avanço da OTAN e da UE para as bordas da Rússia (principalmente após a adesão de Romênia, Polônia, Bulgária e os três países bálticos nos anos 2000), e o flerte da Moldávia e da Ucrânia com os referidos blocos acionaram o alerta em Moscou de que a região poderia, enfim, passar a ser controlada pelos países ocidentais, em especial os EUA, rival histórico da Rússia. Trenin (2011) demonstra qual o sentimento nacional russo em relação a Washington e à OTAN:

[... a crença entre a elite política russa de que o objetivo principal dos EUA ainda permanece o mesmo de sempre: humilhar a Rússia o máximo que puder e, se for possível, decom- 
pô-la em pedaços e subordiná-la aos desejos norte-americanos. Essa é uma interpretação grosseira, é claro, mas é a essência da pauta da política externa dos EUA. [...] O alargamento da OTAN é parte de um plano para cercar, enfraquecer, pressionar a Rússia, e etc. Entrando em um pouco mais de detalhes, verifica-se que a ampliação da OTAN significa a amputação final das extremidades daquele país, uma intromissão na zona de interesses privilegiados russos, criando uma plataforma para o Pentágono (TRENIN, 2011, p. 4849, TRADUÇÃO NOSSA)

$\mathrm{Na}$ concepção russa, trata-se de garantir a segurança do país, que vê ameaças à identidade dos russos étnicos da Crimeia, a seus interesses econômicos, à estabilidade política e, principalmente, ameaças estratégico-militares.

O caso da Crimeia guarda grandes semelhanças com a questão transnístria. Trenin (2001) observa que são três os interesses russos em relação à região: geopolítico, geoestratégico e humanitário. $\mathrm{O}$ interesse geopolítico significa exercer influência sobre a Transnístria de forma a conseguir controlar a Moldávia, através da sua participação na Comunidade dos Estados Independentes (CEI) e de acordos políticos e econômicos bilaterais, além de prevenir sua fusão com a Romênia. O geoestratégico refere-se à manutenção da presença militar na área para prevenir a acessão da Moldávia à OTAN. Por último, o interesse humanitário relaciona-se à garantia de um tratamento justo dos russos que habitam a região, o que, na verdade, equivale à preservação da identidade especial da Transnístria. Com a aproximação moldava do Ocidente, o Kremlin entende que a única forma de manter certa influência sobre o país é exercendo algum tipo de dominação sobre o regime separatista de Tiraspol. Por essa razão Moscou mantém um interesse firme em um arranjo constitucional na Moldávia que eleve o status da Transnístria para a de um ente federado.
O último elemento de semelhança é a economia. Por meio das duas regióes, a Rússia consegue salvaguardar ganhos econômicos no setor de maior destaque do país: o energético. Na Crimeia, há um grande potencial inexplorado de recursos energéticos que a Rússia só poderá se valer ao obter o controle total da regiāo. A rapidez com que respondeu à solicitação dos habitantes crimerianos para a anexação é interpretada por muitos analistas como um desejo de apropriar-se da área onde, recentemente, foram identificadas novas bacias de petróleo e gás natural (BEBLER, 2015). Na Transnístria, a situação é um pouco distinta: não há recursos naturais inexplorados. Porém, os principais gasodutos que ligam a Rússia à Moldávia passam por ali. Assim, ao manter seu domínio sobre o regime de Tiraspol, a Rússia consegue pressionar Chisinau a agir conforme seus interesses, já que a dependência excessiva que a Moldávia tem do gás russo a deixa com poucas opçóes nesse tabuleiro.

Percebe-se, desse modo, que manter a Transnístria e a Crimeia sob o domínio russo serve ao projeto de poder da política externa do país, cimentando sua influência sobre a região do Mar Negro. $\mathrm{O}$ recente alargamento da OTAN e da UE para próximo das portas da Rússia determina uma atuação incisiva na região. Assim, apesar das diferenças, o tratamento conferido à Crimeia e à Transnístria tem um objetivo comum: assegurar seu poder sob uma área estratégica ameaçada pela expansão das potências ocidentais.

\section{As particularidades dos casos da Crimeia e da Transnístria}

Apesar das semelhanças entre as duas situações, é possível perceber a diferença de tratamento conferido por Putin aos dois casos. Diferentemente do que entende o comando da OTAN, que afirmou que "a Rússia tem uma grande força na 
fronteira leste da Ucrânia e há uma grande preocupaçáo que ela possa representar uma ameaça à região separatista de Transnístria" (CROFT, 2014), a incorporação da Transnístria pela Federação Russa é improvável, pois não se coaduna com seus objetivos sobre a Moldávia.

Em primeiro lugar, é notável o fato de a Rússia recusar-se a reconhecer a independência transnístria, preferindo apoiar futuras negociaçôes que decidirão o status da regiáo autônoma. Cabe mencionar uma breve passagem de Devyatkov:

O vice-ministro das Relaçôes Exteriores, Sergei Gubarev, anunciou que, se a Transnístria quiser independência, ela deveria ir para a Lua. O Ministro russo das Relaçôes Exteriores, Lavrov, também emitiu uma notória declaração: "a verdade encontra-se em algum lugar. Mas é absolutamente claro que nenhuma instituição internacional apoia a ideia de independência transnístria ou da Moldávia como um Estado unitário. Nós deveríamos tentar encontrar um status especial (DEVYATKOV, 2012,p. 57,TRADUÇÃO NOSSA)

O governo russo entende que, ao apoiar a independência transnístria, abriria precedentes para as regióes da Rússia que também desejam separação, como é o caso da Chechênia, república russa do norte do Cáucaso; que declarou sua independência em 1991, desencadeando conflitos armados em 1994 e 2003. Para evitar novos conflitos no interior do país - vale lembrar que a Chechênia é uma importante área produtora de petróleo - os russos preferem não criar pretexto para a secessão.

Os motivos para a não anexação, contudo, são muito mais profundos. Enquanto a Crimeia é área de grande viabilidade estratégica e econômica, a Transnístria tem um fraco potencial demográfico, mercado doméstico reduzido e carência de recursos naturais, em território de apenas $4.000 \mathrm{Km}^{2}$. A economia, tradicionalmente voltada para a exportação de produtos industriais (há grandes indústrias herdadas da Era Soviética), foi duramente afetada pela crise nos países europeus e na Rússia, e a região passou a depender amplamente da ajuda econômica de Moscou. (CALUS, 2013). Além disso, a área não é contígua à Rússia, o que dificultaria ainda mais as relaçôes de Moscou com aquele diminuto território.

Em segundo lugar, uma anexação da região aumentaria muito a probabilidade de a Moldávia - país empobrecido e fortemente dependente da agricultura - anexar-se à Romênia, país com que tem grande proximidade cultural e que já faz parte da UE, o que contraria os interesses russos na Moldávia. A entrada da Romênia na UE, em 2007, estimulou múltiplas solicitações de cidadania romena por moldavos que intencionavam migrar para os países europeus. $\mathrm{O}$ número cada vez maior de moldavos portando a cidadania romena é visto com preocupação pelas autoridades de Chisinau e, em especial, pelo Kremlin, que afirmam que a Moldávia tende a se tornar um país mais e mais romenizado com o passar do tempo.

A aproximação identitária de Moldávia e Romênia também explica o terceiro motivo pelo qual se considera a anexaçấo improvável. Ao incorporar a região à Federação Russa, haveria uma forte reação dos aliados ocidentais. Como a Romênia é o vizinho mais próximo (que possui interesses claros na área, além de contar com um grande número de cidadáos romenos na Moldávia) e faz parte tanto do bloco europeu quanto da OTAN, a resposta poderia ser um conflito armado de grandes proporçóes. De acordo com a avaliação de Mearsheimer (2014), a Rússia não estaria preparada para uma guerra, pois além de ter um exército tecnologicamente inferior ao dos países da OTAN, encontra-se em uma grave crise financeira, que se agravou com as duras sançóes impostas pelos EUA e UE.

Por fim, cabe citar que o motivo mais relevante é estratégico. A Rússia não tem interesse em 
anexar a Transnístria, pois, ao fazê-lo, perderia sua influência em toda a Moldávia, o que contraria os interesses do Kremlin. O país recusa-se a acatar qualquer processo de paz, uma vez que a resoluçáo do conflito conduziria Chisinau para os braços da OTAN. Maria Raquel Freire (2011) faz uma interessante análise a respeito do papel russo no processo de paz moldavo-transnístrio:

A estratégia russa é uma resposta dupla às exigências de respeito pela integridade territorial, não esquecendo os desafios separatistas no interior da própria Rússia, mas também ao desejo de controle e influência no espaço pós-soviético, onde a perpetuação dessa situação permite margem de manobra a Moscou, conferindo-lhe poder adicional sobre as autoridades em Chisinau e mantendo uma presença militar às portas da Europa e bem próximo dos Bálcâs (FREIRE, 2011, p.85)

De forma similar, Kaljurand (2008) mostra os reais interesses russos:

Historicamente, a Moldávia pertence à esfera de influência russa e, como os outros países da CEI, constitui um tijolo no paredão da Rússia contra a OTAN. A intenção da Rússia, portanto, tem sido sempre de manter o controle sobre essas áreas e integrá-las à sua própria rede de segurança. [...] A Rússia está usando o conflito territorial não resolvido da Transnístria como uma ferramenta de barganha. O preço para a resolução do conflito é uma estrutura federal para a Transnístria, direitos substanciais para os parlamentares transnístrios, reconhecimento da propriedade russa na Transnístria, um status especial para a língua russa e compromisso com alianças não militares permanentes (KALJURAND, 2008, p. 04, TRADUÇÃO NOSSA). ${ }^{5}$

5. Historically, Moldova belongs to Russia’s sphere of influence and, like other CIS countries, makes up one brick in Russia's buffer wall against NATO. Russia's intention has therefore always been to keep control over these areas and integrate them into its own security network. [...] Russia is using the unresolved territorial conflict of Transnistria as a bargaining tool. The price for the resolution of the conflict is a federal framework for Transnistria, substantial rights for Transnistrian parliamentarians, recognition of Russian property in Transnistria, special status for the Russian language and commitment to permanent military non-alliance
Conclui-se, portanto, que anexar a Transnístria é um fato altamente improvável, pois manter a situação da Transnístria congelada é de interesse da Rússia. A razão para o conflito transnístrio não ter sido resolvido até os dias de hoje é predominantemente estratégica: ao manter o conflito congelado, a Rússia afasta a Moldávia da OTAN, que, como já citado, não aceita membros com problemas fronteiriços. Além disso, uma eventual anexaçáo tiraria o poder russo de influenciar diretamente sobre Chisinau. Essa é a mesma motivação da Rússia em anexar a Crimeia: ao incorporar a península ao território russo, torna-se impossível a adesão da Ucrânia à OTAN. Percebe-se, assim, que, apesar da diferença de atitude em relaçấo aos dois casos - anexação na Crimeia e não anexação na Transnístria - o intuito é o mesmo: permitir que eles não sejam atraídos pela aliança atlântica, o que manterá os dois países sob a influência de Moscou por tempo indeterminado.

\section{Referências}

BEBLER, Anton. Crimea and the Russian-Ukrainian conflict. Romanian Journal of European Affairs, v. 15, n. 1, 2015.

CALUS, Kamil. An aided economy: the characteristics of the transnistrian economic model. Centre of European Studies, n. 108, 2013.

CIOBANU, Vitalie. Quo vadis, Moldova? Lviv: European Integration Studies Centre, Multi-M Publishing House, 2007.

CROFT, Adrian. OTAN alerta para ameaça russa à regiáo separatista na Moldávia. [S. 1.]: Noticias R\&, 2014.

DEVYATKOV, Andrey. Russian Policy Toward Transnistria: between multilateralism and marginalization. Problems of Post-Comunism, v. 59, n. 03. p. 53-62, 2012.

ENGLUND, Will; LALLY, Kathy. Putin says he reserves right to protect Russians in Ukraine. [S. 1.]: The Washington Post. Kiev, 2014.

FREIRE, Maria Raquel. A Rússia de Putin: vectores estruturantes de política externa. Coimbra: Almedina, 2011.

GONZÁLEZ, Ángel P. Minorías rusas em la antigua URSS. Afers Internacionals, n. 51-52, p. 25-43, 2001.

KALJURAND, Riina. Russian influence on Moldovan politics during the Putin Era (2000-2008). International Centre for Defense Studies, 2008. 
MEARSHEIMER, John J. Why the Ukraine crisis is the West's fault: the liberal delusions that provoked Putin. Foreign Affairs, v. 93, n. 5, p. 1-12, 2014.

MEFFORD, Brian. Analysing annexation targets in Ukraine and frozen conflicts, 2014.

MIELNICZUK, Fabiano. A crise ucraniana e suas implicaçôes para as Relaçôes Internacionais. Revista Conjuntura Austral, v. 5, n'. 23, 2014.

NYGREN, Bertil. The Rebuilding of Greater Russia: Putin's foreign policy towards the CIS Countries. New York: Routledge, 2007.

RUSSIA. Ministério das Relaçôes Exteriores da Federação Russa. The Foreign Policy Concept of Russian Federation. Moscou, 2013. Disponível em: <http://archive.mid.ru//brp 4. nsf/0/76389FEC168189ED44257B2E0039B16D>. Acesso em: 12 Mar 2016.

TRENIN, Dmitri. The End of Eurasia: Russia on the border between geopolitics and globalization. Washington: Carnegie Moscow Center, 2001.

TRENIN, Dmitri. Russia and the New Eastern Europe. Russian Politics and Law, v. 49, n. 6, 2011.

TRENIN, Dmitri. The Ukraine Crisis and the resumption of Great-Power rivalry. Carnegie Moscow Center. Moscou, 2014. 